\title{
Nutritional Influence on Childhood Development and Genetic Control of Adolescent Growth of Quechuas and Mestizos From the Peruvian Lowlands
}

\author{
A. ROBERTO FRISANCHO, KENNETH GUIRE, WILLIAM BABLER, \\ GARY BORKAN, AND ANTONY WAY \\ Center for Human Growth and Development and Department of Anthropology, \\ University of Michigan, Ann Arbor, Michigan 48109 (A.R.F. and K.G.); \\ Department of Plastic Surgery, University of Virginia, Charlottesville, Virginia \\ 22901 (W.B.); Normative Aging Study, Veterans Administration Hospital, \\ Boston, Massachusetts 021:30 (G.B.); and Department of Preventive Medicine \\ and Community Health, Texas Tech University School of Medicine, Lubbock, \\ Texas 79430 (A.W.).
}

\author{
KEY WORDS Growth, Peruvian, Quechuas, Mes- \\ tizos, Nutritional status, Genetics
}

\begin{abstract}
The growth in height of 1,202 Quechua and Mestizo children aged 6 to 19 years of the province of Lamas in the Peruvian Eastern Lowlands was studied. As shown by evaluations of $\mathrm{ABO}$, Rh systems, and skin reflectance measurements, the Quechuas are genetically different from the Mestizos. The heights of Quechuas and Mestizos were matched for nutritional status based on measurements of subcutaneous fat and body muscle. The study indicates that: 1) during childhood, Quechuas and Mestizos matched for the same nutritional status attain similar heights; 2) during adolescence (or after the age of 11 years), the Mestizos are significantly taller than the Quechuas of the same nutritional status; 3) during childhood, the relative difference in height between Quechuas and Mestizos matched for the same nutritional status is less than the difference between Quechuas (or Mestizos) of the same genetic composition characterized by good and poor nutritional status.

These findings suggest that the influence of environmental factors, such as nutrition, have a greater influence in producing differences in body size during childhood than during adolescence. Conversely, the present findings support the hypothesis that the influence of genetic factors on body size are greater during adolescence than during childhood. However, comparison of adolescent samples of similar genetic composition (whether they be Quechuas or Mestizos), characterized by good and poor nutritional status, reveal large differences in height, suggesting that under conditions of malnutrition, the genetic control of growth is diminished.
\end{abstract}

One of the major goals of research in human growth is to determine the relative effects of hereditary and environmental factors upon size and shape. Various studies have demonstrated that under optimal conditions of nutrition and health, genetic factors play an important role in influencing variations in growth and development (Garn and Rohman, '66; Hunt, '66). In the same manner, several investigations have documented the profound effects of environmental factors on human growth and function (Frisancho and Baker, '70; Frisancho, '78a; Malcolm, '69, '70). Comparative analysis of children of diverse genetic backgrounds exposed to comparable socioeconomic conditions suggest that variations in height and weight is regulated primarily by environmental factors (Habicht et al., '74). The hypothesis that growth differences during childhood reflect the influence of environmental factors is supported by the finding that among populations exposed to chronic malnutrition, the delay in skeletal maturation is greater during childhood than during adolescence (Frisancho, et al., ' $70 \mathrm{a}, \mathrm{b}$ ). Based on a study of upper class Guatemalan youths of Guatemalan and European ancestry, Johnston et al. ('75, '76) suggested that the role of genetic factors in influencing growth differ-

Received March 12, 1979; accepted August 8, 1979 
ences in height are more important during adolescence than during childhood. However, none of these studies includes assessments of nutritional status, and interpretation of the results in genetic and environmental terms is difficult. In this paper, we report the results of a study of the growth in height of two genetically dissimilar samples from the Peruvian Lowlands matched for nutritional status, and genetically similar samples of unequal nutritional status.

\section{MATERIALS AND METHODS}

\section{Subject population}

The subject population was drawn from the town of Lamas, one of the seven districts of the province of Lamas of the Department of San Martin, Peru. As indicated by the 1961 Peruvian Census, the population of the district of Lamas was 12,866 of which 7,139 live in the central town of Lamas and 5,727 are distributed on the aggregated native-owned settlements. The town of Lamas is situated at an altitude of 1,320 meters above sea level, which is one of the highest populated locations in the province of Lamas. The climate is that of moderate heat stress. The average annual temperature is about $27^{\circ} \mathrm{C}$, with a relative humidity of about 50 per cent. The population of the town consists of two distinct and separated ethnic groups: the Quechuas and the Mestizos.

Most of the Quechua population lives in the southwest part of the town known as Wayko. As indicated by historical accounts, this Quechua-speaking population descended from the ancient Chanca tribes who migrated from the Central and Southern Highlands after they were defeated by the Incas about 500 years ago (Markham, '11; Isquierdo, '60; Vasquez, '49; Weis, '59). Evaluation of the ABO and Rh gene systems indicated that the Quechuas from Lamas are indistinguishable from the highland Quechuas (Frisancho and Klayman, '75). The Mestizo population consists of Spanishspeaking inhabitants who have settled in the region since the Spanish conquest. According to Isquierdo ('60), Captain Martin de la Riva y Herrera was the first Spaniard to settle in the region and in 1650 founded the town of Lamas. Subsequently, the town of Lamas was populated by Mestizos from the Peruvian Coastal and Highland regions. At present, the Quechua speaking people of Lamas do not intermarry with the Mestizos, so that a strict tribal endogamy is maintained. Marriage between a Quechua and Mestizo is forbidden by the Quechuas, though not by the Mestizos. Analy. sis of genealogical information of about 500 families confirms this endogamy of the Quechuas.
Quechua sample: The study included a sample of 476 Quechua children ranging in age from 6 to 19 years. They attended the schools of Lamas and the ages of the subjects were derived from birth records provided by school officials.

Mestizo sample: The Mestizo sample included 726 Mestizo children ranging in age from 6 to 19 years, attending the schools of Lamas. These ages were also derived from birth records provided by school officials.

Evaluations of ABO blood phenotypes (Frisancho and Klayman, '75) indicate that about 94 per cent of the Quechuas are of type $O$ and only 5 and 1 per cent have types A and B, respectively. In contrast, about 60 per cent of the Mestizos have blood of type O, 20 per cent of type A, and 10 per cent of type B. Furthermore, measurements of skin reflectance at the inner arm with the red and blue filter indicated that the Quechuas are about 25\% darker than the Mestizos.

Based on data of $\mathrm{ABO}$ and PTC phenotypes skin color reflectance we have calculated that the Quechuas and Mestizos, as assessed by the Mahanobis $\mathrm{D}^{2}$ (Nei, '72), have a biological distance of $\mathrm{D}=0.47$, which is twice the expected value for related populations. Thus the ABOphenotypes, geneological characteristics, last names, anthroposcopic traits, and geographical residence in the province of Lamas suggest that the delineation of Quechuas and Mestizos into separate populations has validity.

\section{Anthropometric measurements}

The subjects were measured by standard anthropometric techniques (Weiner and Lourie, '69). Measured were height $(\mathrm{cm})$, weight $(\mathrm{kg})$, sitting height $(\mathrm{cm})$, leg and arm length $(\mathrm{cm})$, chest circumference $(\mathrm{cm})$, calf and upper arm circumference $(\mathrm{mm})$, and skinfold thickness (mm), at the triceps, sub-scapula, midauxiliary and calf. Following previous investigations, measurements of the upper arm circumference and triceps skinfold thickness were used to calculate the upper arm muscle area (Frisancho, '74a; Frisancho, et al., '77a, b). The thickness of skinfolds at the four sites were added to give the sum of skinfold thickness. This article is based upon the analysis of height, sum of skinfold thickness, and upper arm muscle area.

\section{Nutritional status}

Previous investigations on experimental animals and human beings have shown that subcutaneous fat and body muscle are positively associated with advanced dimensional growth and advanced maturation under condi- 


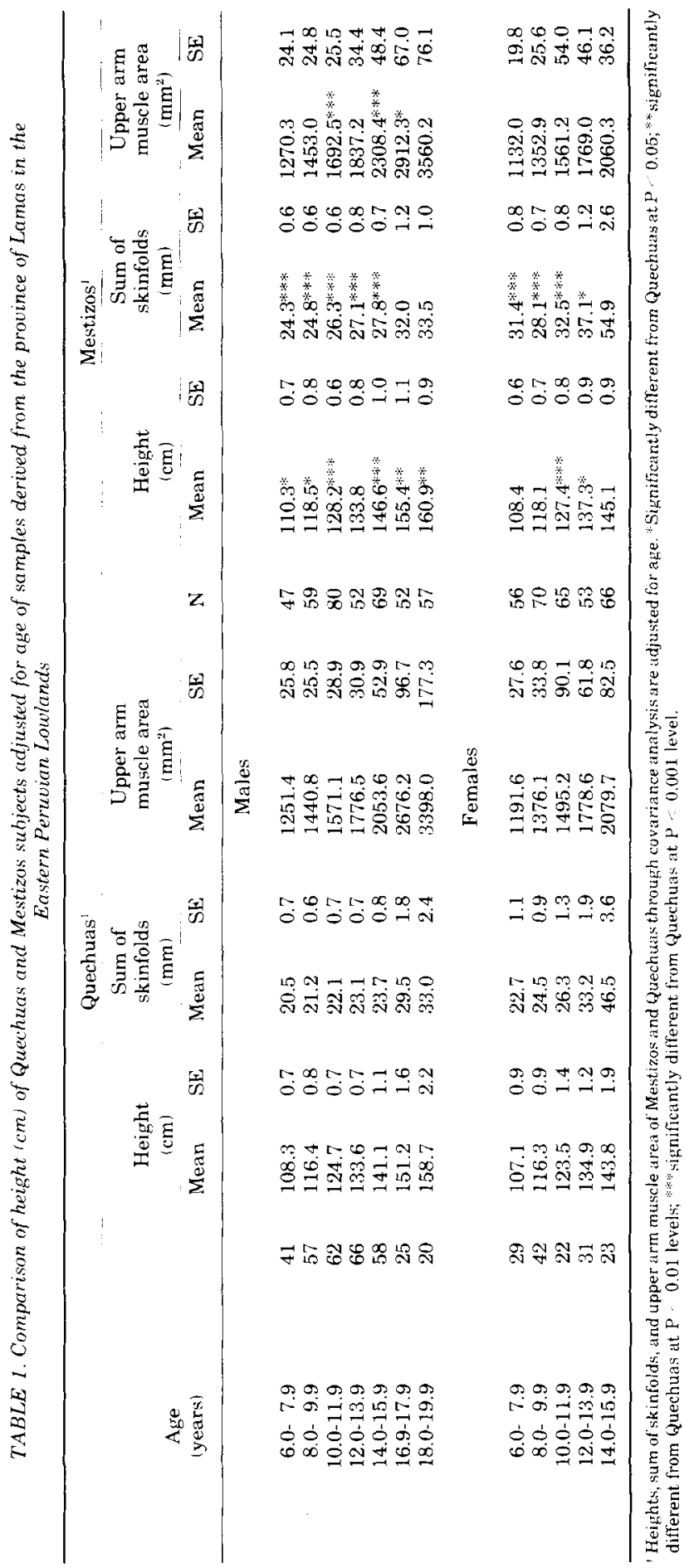


tions of good and poor nutrition (Waterlow and Mendes, '57; Standard et al., '59; Arroyave and Castellanos, '61; Jelliffe, '66; Stini, '72; Dugdale et al., '70; Frisancho et al., '71; Frisancho and Garn, '71; Frisancho et al.,'77a, b; Frisancho, '74a; Garn et al., '75; Johnston and Beller, '76; Martorell et al., '76). Furthermore, these investigations have shown that, under conditions of nutritional restriction, body fat and muscle are utilized by the organism as sources of calories and amino acids for the production of energy and syntheses of protein. For these reasons, the amount of body fat and body muscle are considered as the organism's reserves of calories and protein. Based on these findings, measurements of skinfold thickness and muscle are used as general indices of nutritional status in the present study.

\section{RESULTS}

\section{Height, fat, and muscle}

Table 1 presents the mean and standard error of height, sum of skinfold thickness and upper arm muscle area of the Quechuas and Mestizo samples. The statistical significance of the differences between the samples was tested using age-adjusted values in a one way analysis of covariance. These data show that, between the ages of 8 and 19 years, the Mestizo males are significantly taller than the Quechuas. The Mestizos between the ages of 6 and 16 years are also significantly fatter than are the Quechuas. Similarly, the Mestizos exceed their Quechua counterparts in muscle area between the ages of 10 and 18 years.

Among females, Mestizos are taller than the Quechuas between the ages of 10 and 14 years. Between the ages of 6 and 14 years the Mestizos are also significantly fatter than the Quechuas. In terms of upper arm muscle area, Quechuas and Mestizos attain similar values.

\section{Different genetic composition and equal nutritional status}

To control for the influence of differences of nutritional factors, the Quechuas and Mestizos were matched for nutritional status in the following manner. First, the subjects were grouped into 1-year age groups (i.e., 6.0-6.9 years) and within each age group, the Quechua and Mestizo subjects were matched to the nearest $4 \mathrm{~mm}$ of sum of skinfolds thickness and to the nearest $50 \mathrm{~mm}^{2}$ in upper arm muscle area. If in one group of Quechuas or Mestizos, more than one subject had the same amount of fat or muscle as a subject in the other group, rather than selecting one of them all were in-

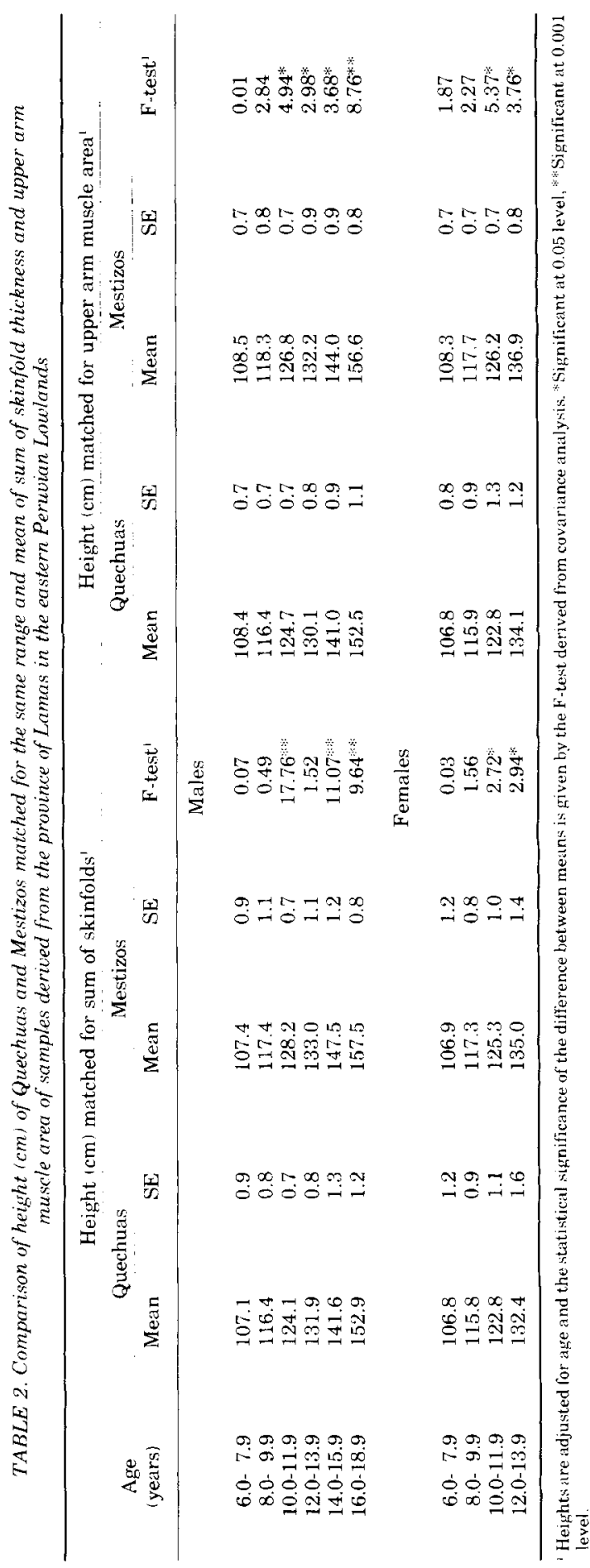


cluded in the sample. Second, the subjects were grouped into 2-year age groups $(6.0-7.9$, etc.) and the mean heights of the Quechuas were compared to those of the Mestizos, statistical significance of the difference being tested by the F-ratio derived from analyses of covariance. Since the mean heights of the Quechuas are compared to those of the Mestizos of an equal projected age, possible variations in the subjects' ages are not reflected in the comparisons of the heights.

Table 2 compares the heights of Quechuas and Mestizos matched for the same upper arm muscle area or sum of skinfold thickness and gives the F-ratios derived from analysis of covariance. From these data, the following points are evident: First, at the same level of fatness the Mestizo and Quechua males between the ages of 6 and 9 , and 12 and 13 years attain similar heights. Thereafter, the Mestizos are significantly taller than the Quechuas. Second, the Mestizo and Quechua females, at the same level of fatness until the age of 9 years, are indistinguishable in height, but between the ages of 10 and 14 years, the Mestizos are significantly $(\mathrm{P}<0.001)$ taller than their Quechua counterparts. Third, at the same level of upper arm muscle area, the Quechua and Mestizo males between the ages of 6 and 9 years attain similar heights, but after the age of 11 years, the Mestizos are significantly taller than the Quechuas. Fourth, among females at the same level of muscle area, the Mestizos after the age of 9 years are significantly taller than are their Quechua counterparts.

The heights of the Quechuas and Mestizos were also regressed on age in a linear fashion

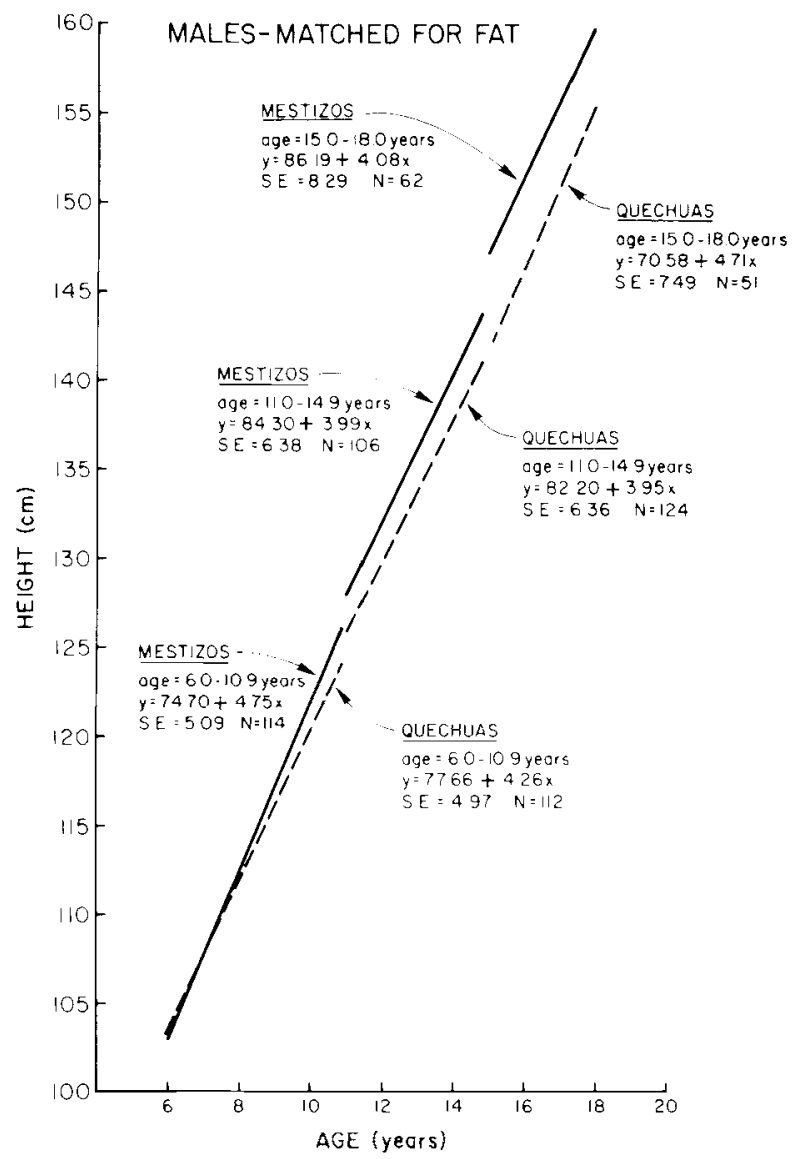

Fig. 1. Comparison of growth in height of Quechua and Mestizo boys, characterized by different genetic composition but similar nutritional status. Note that up to the age of 11 years, both Quechuas and Mestizos have similar heights, but thereafter, the Mestizos are taller than the Quechuas. 


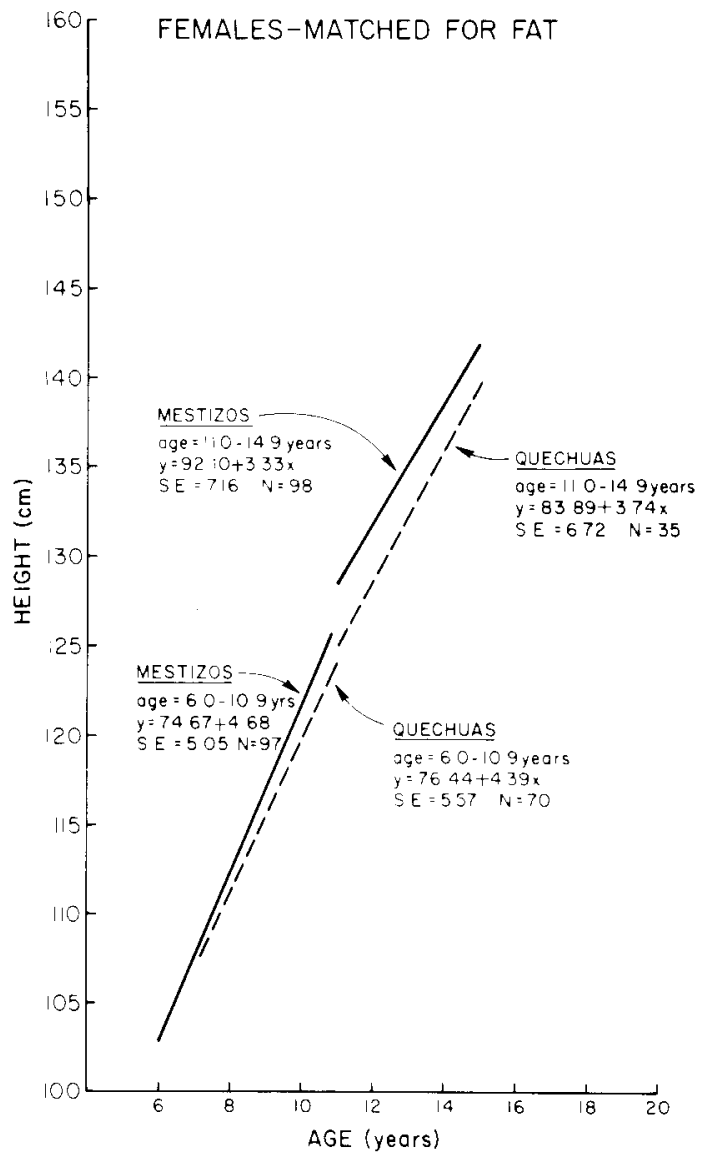

Fig. 2. Comparison of growth in height of Quechua and Mestizo girls, characterized by different genetic composition but similar nutritional status. Like the boys, up to 10 years, Quechua and Mestizos attain similar height, but thereafter, the Mestizos are taller than the Quechuas.

and separated into three groups: $6.0-10.9$, $11.0-14.9$, and $15.0-18.9$ years. We have employed the linear regression technique because the sample is cross-sectional and among these three age groups, growth occurs in almost linear functions of age. Figures 1 and 2 compare the regression equation describing the relationship of age and height of Quechuas and Mestizos matched for the same sum of skinfold thickness. These data show that in both sexes, until the age of 10 years, the increase in height in the Quechuas and Mestizos is quite similar. However, after the age of 11 years, the Mestizos at every age are significantly taller than the Quechuas.

\section{Equal genetic composition and different nutritional status}

Another way of separating the role of genetic and nutritional factors on growth is to compare the heights of children of the same genetic composition but of different nutritional status. With this purpose, we have classified the Quechuas and Mestizos separately into two categories of nutritional status: good nutritional status and poor nutritional status. The subjects were classified as either of good nutritional status or of poor nutritional status depending on whether their sum of skinfold thickness and upper arm muscle area were greater or below the age, sex, and population specific mean values for these respective measurements.

Table 3 presents the per cent difference in height derived from comparisons of height of: 1) Quechuas and Mestizos characterized by different genetic composition, but equal nutritional status; 2) Quechuas of equal genetic composition but having different nutritional status; and 3) Mestizos of equal genetic compo- 
sition but different nutritional status. From these data, the following points are evident: First, during childhood (or before the age of 11 years), the relative difference (calculated by expressing the difference between two values as a percentage of the higher value) in height between the Quechuas and Mestizos having the same nutritional status averages $1.1 \%$ for males and $0.7 \%$ for females. In contrast, the relative difference between the Quechuas of good and poor nutritional status averages $5.2 \%$ for males and $4.7 \%$ for females. Similarly, the relative difference for the Mestizos of good and poor nutritional status averages $3.7 \%$ for males and $5.0 \%$ for females. In other words, during childhood the heights of Quechuas and Mestizos characterized by the same nutritional status are closer, despite genetic differences, than are the heights of Quechua (or Mestizo) children having different nutritional status but similar genetic backgrounds. Second, during adolescence (or after the age of 11 years), the relative difference in height between Quechuas and Mestizos having the same nutritional status averages between 1.9 to $3.9 \%$ for males and $2.2 \%$ for females. However, the relative difference in height between Quechuas of good and poor nutritional status averages $6.1-6.7 \%$ for males and $6.4 \%$ for females. Among Mestizos of good and poor nutritional status, the relative difference in height averages between 6.3 and $7.4 \%$ for males and $5.6 \%$ for females. In other words, when the nutritional status is poor, growth during adolescence is retarded. These findings suggest that under conditions of malnutrition, the adolescent genetic influence on growth in height is diminished.

\section{DISCUSSION}

From this extensive study, it is clear that when the Quechuas and Mestizos are matched for upper arm muscle area and sum of skinfold thickness, childhood differences in stature are minimized. This finding suggests that childhood differences in stature between Quechuas and Mestizos are related mostly to differences in calorie (measured by body fat) and protein (measured by body muscle) reserves and that ethnic genetic differences play a minor role. On the other hand, during adolescence, the Mestizos and Quechuas show significant differences in stature despite the fact that these samples were matched for the same amount of fatness and muscularity. Habicht et al. ('74), comparing the growth in height and weight of preschool children of diverse genetic backgrounds exposed to similar socioeconomic

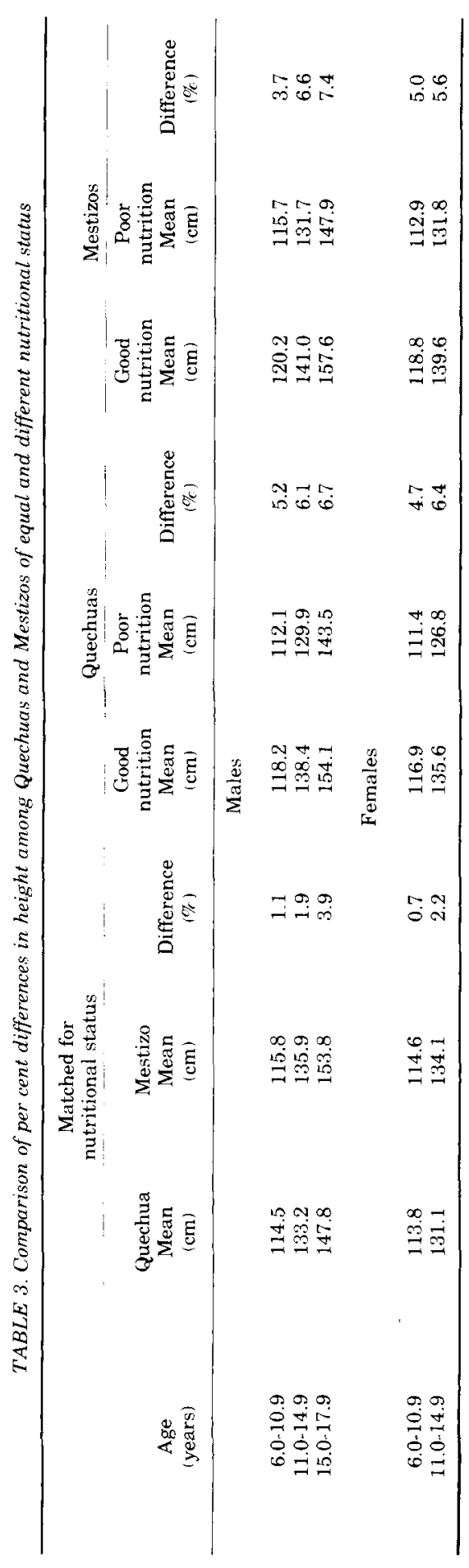


conditions, found no population differences Similarly Johnston et al. ('75, '76) found that the growth in height of North American children living in Guatemala city before adolescence was more similar to the genetically different Guatemalan children of high socioeconomic status, than to their genetic counterparts in the United States. However, during adolescence, the North American children raised in Guatemala grew in a manner more similar to the North American sample than to the Guatemalans. Based on these findings Johnston et al. (75, '76) postulated that during adolescence, the role of genetic factors in growth in height becomes more important than during childhood, and this finding is supported by the present study. On the other hand, the fact the adolescent Quechuas and Mestizos of poor nutritional status are significantly shorter than their counterparts of good nutritional status indicates that under conditions of poor nutrition, the role of genetic factors on growth in height is overridden by the influence of environmental factors. In other words, only under conditions of good nutrition is the genetic role on adolescent growth in height manifested. These findings also suggest that among populations of good nutritional status, differences in height during adolescence might reflect the influence of population genetic differences. Otherwise, population differences in height during adolescence would reflect only the cumulative effect of chronic undernutrition suffered during childhood (Frisancho, '78b, '79). Indeed, interpretation of differences in height among world populations without concurrent evaluations of nutritional status or environmental factors is very difficult.

The hypothesis that under favorable conditions of nutritional status, the role of genetic factors in growth in height is more important during adolescence than during childhood is in accord with quantitative genetic information and adaptive theory. Evaluation of parentoffspring correlation coefficients demonstrates that at birth and during childhood, the similarities in body size between parents and offspring are much less than those during adolescence (Tanner, '78; Garn and Rohmann, '66). These associations indicate that the genetic contribution to phenotypic variation in height assert themselves more during adolescence than during childhood (Hunt, '66). As such, the respective contribution of genetic and environmental factors on phenotypic variation depends on the developmental stage of the organism, and in general the earlier the age, the greater the influence of the environment
(Frisancho, '79). Conversely, the later the age of the organism, the greater the influence of genetic factors.

\section{ACKNOWLEDGMENTS}

We thank the school children, directors, and teachers of the schools of the province of Lamas for their cooperation in this study. We also acknowledge assistance from Jane Klayman, Fran Steir, and William Lowe, graduate students of the Department of Anthropology of the University of Michigan, and Jorge Sanchez of the Department of Anthropology of the University of Cuzco, Peru in the collection of data. We also thank Robert Wainwright, Margaret Owen, and Nancy Becker for their assistance in manuscript preparation.

The investigation has been supported in part by grant GS-37524X of the National Science Foundation.

\section{LITERATURE CITED}

Arroyave, G., and $\mathrm{H}$. Castellanos (1961) Role of the adrenal cortical system in the response of children to severe protein calorie malnutrition. Am. J. Clin. Nutr., 9:186-195.

Dugdale, A.E. (1970) An age-independent anthropometric index of nutritional status. Am. J. Clin. Nutr., 24:174176.

Frisancho, A.R. (1974a) Triceps skinfold and upper arm muscle size norms for assessment of nutritional status. Am. J. Clin. Nutr., 27: 1052-1058.

Frisancho, A.R. (1974b) Functional adaptation to high altitude hypoxia. Science, 187:313-319.

Frisancho, A.R. (1978a) Human growth and development among high-altitude populations. In: The Biology of High-Altitude Peoples, P.T. Baker, ed. Cambridge University Press, New York.

Frisancho, A.R. (1978b) Nutritional influences on human growth and maturation. Yrbk Phys. Anthropol., 21:174191.

Frisancho, A.R. (1979) Human Adaptation. A Functional Interpretation. C.V. Mosby Company, St. Louis, Missouri. Frisancho, A.R., and P.T. Baker (1970) Altitude and growth; a study of the patterns of physical growth of a high altitude Peruvian Quechua population. Am. J. Phys. Anthropol, 32.279-290.

Frisancho, A.R., and S.M. Gam (1971) Skinfold thickness and muscle size: Implications for developmental status and nutritional evaluation of children from Honduras. Am. J. Clin. Nutr., 24:541-546.

Frisancho, A.R., S.M. Garn, and W. Ascoli (1970a) Childhood retardation resulting in reduction of adult body size due to lesser adolescent skeletal delay. Am. J. Phys. Anthropol., $33: 325-336$.

Frisancho, A.R., S.M. Garn, and W.A. Ascoli (1970b) Unequal influence of low dietary intakes on skeletal maturation during childhood and adolescence. Am. J. Clin. Nutr., 23: $1220-1227$.

Frisancho, A.R., S.M. Garn, and L.D. McCreery (1971) Relationship of skinfolds and muscle size to growth of children. I. Costa Rica. Am. J. Phys. Anthropol., 35:85-90.

Frisancho, A.R., and J.E. Klayman (1975) A-B-O and Rh affinities between Highland and Lowland Quechua speak ing Peruvian populations. Am. J. of Phys. Anthropol., 43:285-289. 
Frisancho, A.R., J.E. Klayman, and J. Matos (1977a) Influence of maternal nutritional status on prenatal growth in a Peruvian urban population. Am. J. Phys. Anthropol., 46:265-274.

Frisancho, A.R., J.E. Klayman, and J. Matos (1977b) Newborn body composition and its relationship to linear growth. Am. J. Clin. Nutr., 30:704-711.

Garn, S.M., and C.G. Rohmann (1966) Interaction of nutrition and genetics in the timing of growth and development. Pediat. Clin. N. Amer., 13:353-379.

Garn, S.M., D. Clark, and K.E. Guire (1975) Growth, body composition, and development of obese and lean children. In: Childhood Obesity. M. Winick, ed. Wiley, New York.

Habicht, J.P., R. Martorell, C.L. Yarbrough, R.M. Malina, and R.E. Klein (1974) Height and weight standard for preschool children. How relevant are ethnic differences in growth potential? Lancet, 1:611-615.

Hunt, E.E. (1966) The developmental genetics of man. In: Human Development. F. Falkner, ed. W.B. Saunders, Philadelphia.

Isquierdo, G. (1960) El Indio de Lamas. Imprenta La Oriental Tarapoto, Peru.

Jelliffe, D.B. (1966) The assessment of the nutritional status of the community. WHO Monograph, series \#53, (geneva) $53: 228$.

Johnston, F.E., and A. Beller (1976) Anthropometric evaluation of the body composition of black, white, and Puerto Rican newborns. Am. J. Clin. Nutr., 29:61-65.

Johnston, F.E., M. Borden, and R.B. MacVean (1975) The effects of genetic and environmental factors upon the growth of children in Guatemala City. In: Biosocial Interrelations in Population Adaptation. E.S. Watts, F.E. Johnston, and G.W. Lasker, eds. Mouton, The Hague.

Johnston, F.E., H. Wainer, D. Thissen, and R. MacVean (1976) Hereditary and environmental determinants of growth in height in a longitudinal sample of children and youth of Guatemalan and European ancestry. Am. J. Phys. Anthropol., 44:469-476.

Malcolm, L.A. (1969) Growth and development of the Kaiapit children of the Markham Valley, New Guinea. Am. J. Phys. Anthropol., 31:39-51.

Malcolm, L.A. (1970) Growth and development of the Bundi child of the New Guinea Highlands. Human Biol., 42:293-328.

Markham, C.R. (1911) The Incas of Peru. Smith and Elder, London.

Martorell, R.C., C. Yarbrough, A. Lechtig, H. Delgado, and R.E. Klein ( 1976) Upper arm anthropometric indicators of nutritional status. Am. J. Clin. Nutr., 29:46-53.

Nei, M. (1972) Genetic distance between populations. Am. Nat, 106:283-292,

Standard, K.L., V.G. Wills, and J.C. Waterlow (1959) Indirect indications of muscle mass in malnourished infants. Am. J. Clin. Nut., 7:271-279.

Stini, W. (1972) Reduced sexual demorphism in upper arm muscle circumference associated with protein-deficient diet in a South American population. Am. J. Phys. Anthropol., 36:341-352.

Tanner, J.M. (1978) Fetus Into Man, Physical Growth from Conception to Maturity. Harvard University Press, Cambridge, Mass.

Vasquez, M.C. (1949) El primitivo poblador de Huallaga y causas de su extincion. Tesis de etnologia, Universidades de San Marcos, Peru.

Waterlow, J.C., and C.B. Mendes (1957) Composition of muscle in malnourished human infants. Nature (London) 180:1361-1362.

Weis, P. (1959) Los Lamas son un pueblo misteriaso. Peru Indigena 13-16.

Weiner, J.S., and J.A. Lourie (1969) Human Biology: A Guide to Field Methods. Blackwell Scientific Publications, Oxford, England. 